\title{
Internet use by older adults with bipolar disorder: international survey results
}

\author{
Rita Bauer ${ }^{1}$, Tasha Glenn², Sergio Strejilevich³ ${ }^{3}$ Jörn Conell ${ }^{1,4}$, Martin Alda ${ }^{5}$, Raffaella Ardau 6 ,
} Bernhard T. Baune ${ }^{7}$, Michael Berk ${ }^{8,9,10,11,12}$, Yuly Bersudsky ${ }^{13}$, Amy Bilderbeck ${ }^{14}$, Alberto Bocchetta ${ }^{15}$, Angela M. Paredes Castro ${ }^{8,9}$, Eric Y. W. Cheung ${ }^{16}$, Caterina Chillotti 6 , Sabine Choppin ${ }^{17}$, Alessandro Cuomo ${ }^{18}$, Maria Del Zompo ${ }^{15}$, Rodrigo Dias ${ }^{19}$, Seetal Dodd ${ }^{8,9,10}$, Anne Duffy ${ }^{20}$, Bruno Etain ${ }^{21}$, Andrea Fagiolini ${ }^{18}$, Miryam Fernández Hernandez ${ }^{22}$, Julie Garnham ${ }^{5}$, John Geddes ${ }^{14}$, Jonas Gildebro ${ }^{23}$, Michael J. Gitlin ${ }^{24}$, Ana Gonzalez-Pinto ${ }^{22}$, Guy M. Goodwin ${ }^{14}$, Paul Grof ${ }^{25,26}$, Hirohiko Harima ${ }^{27}$, Stefanie Hasse ${ }^{28}$, Chantal Henry ${ }^{21,29}$, Diego Hidalgo-Mazzei ${ }^{30}$, Anne Hvenegaard Lund ${ }^{23}$, Vaisnvy Kapur ${ }^{31}$, Girish Kunigiri ${ }^{32}$, Beny Lafer ${ }^{19}$, Erik R. Larsen ${ }^{33,34}$, Ute Lewitzka', Rasmus W. Licht ${ }^{35,36}$, Blazej Misiak ${ }^{37}$, Patryk Piotrowski ${ }^{37}$, Ângela Miranda-Scippa ${ }^{38}$, Scott Monteith ${ }^{39}$, Rodrigo Munoz ${ }^{40}$, Takako Nakanotani ${ }^{41}$, René E. Nielsen ${ }^{35}$, Claire O'Donovan ${ }^{5}$, Yasushi Okamura ${ }^{27}$, Yamima Osher ${ }^{13}$, Andreas Reif ${ }^{42}$, Philipp Ritter ${ }^{1}$, Janusz K. Rybakowski ${ }^{43}$, Kemal Sagduyu ${ }^{44}$, Brett Sawchuk ${ }^{20}$, Elon Schwartz ${ }^{45}$, Claire Slaney ${ }^{5}$, Ahmad H. Sulaiman ${ }^{46}$, Kirsi Suominen ${ }^{47}$, Aleksandra Suwalska ${ }^{43}$, Peter Tam ${ }^{48}$, Yoshitaka Tatebayashi ${ }^{41}$, Leonardo Tondo ${ }^{49,50}$, Julia Veeh ${ }^{42}$, Eduard Vieta ${ }^{30}$, Maj Vinberg ${ }^{51}$, Biju Viswanath ${ }^{52}$, Mark Zetin ${ }^{53}$, Peter C. Whybrow ${ }^{24}$ and Michael Bauer ${ }^{1^{*}}$ (1)

\begin{abstract}
Background: The world population is aging and the number of older adults with bipolar disorder is increasing. Digital technologies are viewed as a framework to improve care of older adults with bipolar disorder. This analysis quantifies Internet use by older adults with bipolar disorder as part of a larger survey project about information seeking.

Methods: A paper-based survey about information seeking by patients with bipolar disorder was developed and translated into 12 languages. The survey was anonymous and completed between March 2014 and January 2016 by 1222 patients in 17 countries. All patients were diagnosed by a psychiatrist. General estimating equations were used to account for correlated data.

Results: Overall, $47 \%$ of older adults (age 60 years or older) used the Internet versus $87 \%$ of younger adults (less than 60 years). More education and having symptoms that interfered with regular activities increased the odds of using the Internet, while being age 60 years or older decreased the odds. Data from 187 older adults and 1021 younger adults were included in the analysis excluding missing values.
\end{abstract}

Conclusions: Older adults with bipolar disorder use the Internet much less frequently than younger adults. Many older adults do not use the Internet, and technology tools are suitable for some but not all older adults. As more health services are only available online, and more digital tools are developed, there is concern about growing health disparities based on age. Mental health experts should participate in determining the appropriate role for digital tools for older adults with bipolar disorder.

\footnotetext{
*Correspondence: michael.bauer@uniklinikum-dresden.de

${ }^{1}$ Department of Psychiatry and Psychotherapy, University Hospital Carl

Gustav Carus, Technische Universität Dresden, Dresden, Germany

Mark Zetin: Deceased in 2017

Full list of author information is available at the end of the article
} 


\section{Background}

The world's population is living longer, with the percentage of people over age 60 years expected to nearly double from 12 to $22 \%$ between 2015 and 2050 (WHO 2015). Today, up to $25 \%$ of the population with bipolar disorder is age 60 years or older (Sajatovic et al. 2015). Older adults with bipolar disorder differ in the disease onset and clinical course, and most have multiple medical comorbidities especially endocrine, respiratory and cardiovascular conditions (Lala and Sajatovic 2012). Digital technology provides a framework to improve care for older adults with bipolar disorder by enabling remote visits, online psychological interventions, health monitoring, information seeking, peer support groups and self-management tools (Gliddon et al. 2017; Hidalgo-Mazzei et al. 2015; Torous et al. 2016).

In addition to providing help with bipolar disorder, Internet use by older adults in the community may decrease loneliness, and increase social support (Forsman and Nordmyr 2017; Heo et al. 2015). Internet use may also contribute to maintaining health literacy, or the ability to read, understand and act on health information (Kobayashi et al. 2015; Andrus and Roth 2002). Government and health care providers increasingly use the Internet as the primary form of communication about health and social services (Chang et al. 2015). Digital technologies are viewed as a means to maximize independence and facilitate aging in place, including for those with disabilities (Agree 2014; Reeder et al. 2013; Schulz et al. 2015), and to provide cost-effective care for the growing elderly population (Deloitte 2015). Most studies of Internet use involve community dwelling older adults and do not focus on mental illness. As the role of online services and monitoring technologies increases, more understanding of Internet use by older adults with bipolar disorder is needed.

To gain insight into online information seeking by patients with bipolar disorder, we previously surveyed 1222 adult outpatients with bipolar disorder living in 17 countries between March 2014 and January 2016 (Bauer et al. 2016; Conell et al. 2016). Of the patients in the survey, $81 \%$ used the Internet, a percentage similar to that of the general public (Bauer et al. 2016). The purpose of this analysis was to compare Internet use between the older adults, defined as 60 years or older, and younger adults less than 60 years, who completed this survey.

\section{Methods}

The 39-question survey was anonymous, and took about $20 \mathrm{~min}$ to complete. The survey was paper based to maximize participation including of those who do not use the Internet. All participants were recruited locally by their psychiatrist with no online recruitment. The study was approved by institutional review boards according to local requirements. The patients who completed the survey resided in 17 countries. The survey was translated into 12 local languages: Chinese, Danish, Finnish, French, German, Hebrew, Italian, Japanese, Polish, Portuguese, Spanish, and English (versions for US/Canada, UK and Australia). The 1222 surveys were received from patients in Australia $(\mathrm{N}=22)$, Brazil $(\mathrm{N}=100)$, Canada $(\mathrm{N}=109)$, Denmark $(\mathrm{N}=209)$, Finland $(\mathrm{N}=16)$, France $(\mathrm{N}=50)$, Germany $(\mathrm{N}=82)$, Hong Kong $(\mathrm{N}=91)$, India $(\mathrm{N}=30)$, Israel $(\mathrm{N}=46)$, Italy $(\mathrm{N}=80)$, Japan $(\mathrm{N}=35)$, Malaysia $(\mathrm{N}=25)$, Poland $(\mathrm{N}=125)$, Spain $(\mathrm{N}=82)$, UK $(\mathrm{N}=50)$, and the US $(\mathrm{N}=70)$.

The survey questions and methodology were published previously (Bauer et al. 2016; Bauer R et al. 2017; Conell et al. 2016). Since paper-based surveys were used, duplicate data entry was performed to minimize data entry errors. A model to evaluate the differences in Internet use by those age 60 years and older was estimated using the generalized estimating equation (GEE) statistical technique to accommodate imbalances in the number of responses from collection sites, and correlation in survey responses within collection sites. Variables significant at the 0.05 level in univariate analyses were included in the multivariate model estimates. SPSS version 24.0 was used for all analyses.

\section{Results}

1222 patients completed the survey. The patients were $62 \%$ female, had a mean age of 44 years (SD 13.8) ranging between 17 and 86 years, and completed 14 (SD 3.2) years of education. The demographic characteristics are shown in Table 1 . Of the 1222 patients, $81 \%$ used the Internet (976 of 1212 valid responses) (Bauer et al. 2016).

There were 1208 valid responses to both the questions on age and "Do you use the Internet?" Of the 1208 patients, 187 were 60 years or older and of these 88 (47\%) used the Internet. Of the 1021 younger adults, $884(87 \%)$ used the Internet. Table 2 shows the best fitting model to assess differences in Internet use between the older adults and younger adults. The model includes variables for age 60 years or older, years of education, and if bipolar disorder sometimes or frequently interfered with regular activities. The estimated coefficients suggest that if age was 60 years or older, the odds of using the Internet will decrease by $86 \%$, a 1 year increase in education will increase the odds of using the Internet by $30 \%$, and if bipolar disorder interferes with regular activities, the odds of using the Internet will increase by $76 \%$.

Of those who used the Internet, 689/880 (78\%) of younger adults and 59/88 (67\%) of older adults looked for information on bipolar disorder. While this appears 
Table 1 Patient demographics $(\mathrm{N}=1222)^{\mathrm{a}}$

\begin{tabular}{|c|c|c|c|c|c|c|}
\hline & \multicolumn{2}{|c|}{ Age 60 or older $(N=187)$} & \multicolumn{2}{|c|}{ Age 59 or younger $(\mathrm{N}=1021)$} & \multicolumn{2}{|c|}{ All ages $(N=1208)$} \\
\hline & $\mathbf{N}$ & $\%$ & $\mathbf{N}$ & $\%$ & $\mathbf{N}$ & $\%$ \\
\hline \multicolumn{7}{|l|}{ Diagnosis } \\
\hline $\mathrm{BP} \mid$ & 107 & 58 & 657 & 65 & 764 & 63 \\
\hline $\mathrm{BP} \|$ & 70 & 38 & 308 & 30 & 378 & 32 \\
\hline BP NOS & 8 & 4 & 48 & 5 & 56 & 5 \\
\hline \multicolumn{7}{|l|}{ Gender } \\
\hline Female & 120 & 64 & 637 & 62 & 757 & 62 \\
\hline Male & 68 & 36 & 390 & 38 & 458 & 38 \\
\hline \multicolumn{7}{|l|}{ Employment status } \\
\hline Full-time & 31 & 17 & 529 & 52 & 560 & 47 \\
\hline Not full-time & 156 & 83 & 482 & 48 & 638 & 53 \\
\hline \multicolumn{7}{|l|}{ Marital status } \\
\hline Married or living with partner & 112 & 60 & 478 & 47 & 590 & 49 \\
\hline Not married & 76 & 40 & 543 & 53 & 619 & 51 \\
\hline \multicolumn{7}{|l|}{ Income group } \\
\hline Upper income & 14 & 8 & 66 & 7 & 80 & 7 \\
\hline Middle income & 105 & 57 & 487 & 48 & 592 & 49 \\
\hline Lower income & 65 & 35 & 468 & 45 & 533 & 44 \\
\hline \multicolumn{7}{|l|}{ Live alone } \\
\hline Yes & 54 & 29 & 245 & 24 & 299 & 25 \\
\hline No & 131 & 71 & 777 & 76 & 908 & 75 \\
\hline \multicolumn{7}{|l|}{ Mood in last 6 months } \\
\hline Mostly normal & 118 & 63 & 460 & 45 & 578 & 48 \\
\hline Mostly not normal & 69 & 37 & 561 & 55 & 630 & 52 \\
\hline \multicolumn{7}{|c|}{$\mathrm{BP}$ disorder interfered with regular activities } \\
\hline Frequently or sometimes & 89 & 47 & 676 & 66 & 765 & 63 \\
\hline Rarely or never & 99 & 53 & 347 & 34 & 446 & 37 \\
\hline \multicolumn{7}{|l|}{ Confident managing living } \\
\hline Very confident & 89 & 48 & 363 & 36 & 452 & 38 \\
\hline Not very confident & 98 & 52 & 659 & 64 & 754 & 62 \\
\hline \multicolumn{7}{|c|}{ Confident knowing when to see physician } \\
\hline Very confident & 117 & 62 & 578 & 57 & 695 & 57 \\
\hline \multirow[t]{2}{*}{ Not very confident } & 71 & 38 & 445 & 43 & 516 & 43 \\
\hline & $\mathbf{N}$ & Mean (SD) & $\mathbf{N}$ & Mean (SD) & $\mathbf{N}$ & Mean (SD) \\
\hline Years of education & 184 & $13(3.6)$ & 1010 & $14(3.1)$ & 1194 & $14(3.2)$ \\
\hline Age of onset & 186 & 36 (13.6) & 1011 & $25(9.4)$ & 1197 & $27(10.9)$ \\
\hline
\end{tabular}

a 14 patients were missing responses to questions on age or "Do you use the Internet"? All missing values were excluded

similar, insufficient data were available on the older adults for a more detailed statistical analysis.

\section{Discussion}

Older adults with bipolar disorder used the Internet much less frequently than younger adults. Overall, $47 \%$ of older adults used the Internet versus $87 \%$ of younger adults. This finding is consistent with prior research on older adults not specific to bipolar disorder. Internet use by community dwelling older adults is increasing, with studies reporting percentages between 36 and $67 \%$, but remains considerably lower than for younger adults (Levine et al. 2016; Friemel 2016; Yu et al. 2016; Anderson and Perrin 2017; Chang et al. 2015). As in prior research, more education and experiencing symptoms were associated with increased 
Table 2 Explanatory model based on responses from the patients who use the Internet $(N=1208)$

\begin{tabular}{lccl}
\hline Independent variables $^{\mathbf{a}}$ & & & \\
\hline Parameter & Significance & OR & $\mathbf{9 5 \%} \mathbf{C l}$ \\
\hline Intercept & $<0.001$ & 0.136 & $0.053,0.349$ \\
Age 60 years or older & $<0.001$ & 0.141 & $0.082,0.241$ \\
$\begin{array}{l}\text { Bipolar disorder sometimes or } \\
\text { frequently interferes with regular }\end{array}$ & 0.001 & 1.764 & $1.246,2.497$ \\
activities & & & \\
Years of education & $<0.001$ & 1.302 & $1.229,1.380$
\end{tabular}

a Patients with missing values were not included

b 187 patients were age 60 years or older at time of study

Internet use (Yu et al. 2016; Gell et al. 2015; Powell and Clarke 2006; Gallagher and Doherty 2009; Flynn et al. 2006), although symptoms of depression, and cognitive decline may decrease use in older adults (Choi and Dinitto 2013; Levine et al. 2018). Smartphone use by community dwelling older adults is even lower than Internet use, at about 40\% (Anderson and Perrin 2017). In this survey, considering Internet users of all ages, $89 \%$ accessed the Internet to find information about bipolar disorder from a computer compared with $11 \%$ from a smartphone or tablet (Conell et al. 2016).

Older adults are diverse, differing in age, education, income, living situation, employment, and experience with technology. Notably, in a US survey of 567 adults age 60 or older, those who used the Internet were often comfortable doing so, and may have a job requiring computer use (Chang et al. 2015). In an international survey, information technology professionals over age 50 experienced less trouble working with multiple devices than younger workers (Patrizio 2016). However, as in this study, many older adults with or without bipolar disorder do not use the Internet. The reasons are complex and include difficulty learning technical skills, high costs of computers, mobile devices and broadband services, attitudes towards technology, increasing age, language issues for immigrants, cognitive decline, preference for traditional media, low health literacy, and relocation to a nursing home (Kuerbis et al. 2017; Fischer et al. 2014; Levine et al. 2018; Levy et al. 2015; Nimrod 2017; Chang et al. 2015). Some older adults are concerned that technology use will reduce face-to-face interactions, including contact with health care providers, and increase isolation (Kang et al. 2010; Kuerbis et al. 2017).

Regardless of Internet use, older adults view health care professionals as the primary and most trusted source of information (Hall et al. 2015; Medlock et al. 2015). Patients of all ages would prefer to learn about a serious mental illness by direct conversation with their psychiatrist (Hallett et al. 2013). Some older adults do not trust the Internet as a source of health information (Sbaffi and Rowley 2017; Zulman et al. 2011). In studies of patients with a mean age $\geq 50$ years, those with a strong therapeutic relationship with a physician were less likely to search for health information on the Internet (Hou and Shim 2010), and more likely to defer decision making to the physician (Park et al. 2014). In this survey, the primary reason why Internet users of all ages did not seek information about bipolar disorder was because they prefer to rely on information from a physician (Bauer et al. 2016).

Regardless of age, most patients who did not use the Internet in this survey lacked technical skills (Bauer et al. 2016). One option to increase technology use by older adults is to provide training, but there are many serious concerns with novice Internet users. The elderly are such frequent targets for financial fraud that it is considered a public health problem in the US (Burnes et al. 2017; CDC 2015), and the scams targeting older adults have moved online (FBI 2014; Carlson 2007). In 2016, in the US, adults over age 60 were the largest group of victims of Internet crime, and suffered the largest monetary losses (FBI 2016). Factors that increase vulnerability to online fraud include low technical skills, individual traits, cognitive impairment, and depression in older adults (Monteith and Glenn 2016; Lichtenberg et al. 2016). Many older adults are not knowledgeable about Internet security hazards and measures to protect privacy (Grimes et al. 2010; Home Instead 2017; Holtfreter et al. 2015; White et al. 2017). Furthermore, many people of all ages have little understanding of privacy issues related to digital technology. For example, in this survey, $43 \%$ of patients of all ages searched the Internet for information about bipolar disorder because they mistakenly thought they were anonymous online (Conell et al. 2016).

In addition to financial fraud, older adults may fall victim to risky online medical activities. Older adults who are seeking to save money by purchasing expensive prescription drugs online will primarily be presented with rogue pharmacies that do not require a prescription (Monteith and Glenn 2017; Monteith et al. 2016). Some of the risks of using rogue pharmacies include counterfeit drugs, low-quality drugs, unapproved drugs, substitutions of strengths and formulations, drug interactions, adverse reactions, and financial fraud (Mackey and Nayyar 2016; Mackey and Liang 2011; GAO 2014). Another problem area involves the online advertising of unnecessary or inappropriate medical screening tests that are not included in evidence-based guidelines (Lovett et al. 2012; Lovett and Mackey 2013).

Older adults with physical limitations use the Internet less frequently than healthier older adults (Gell et al. 
2015; Levine et al. 2018). Many older adults have vision, hearing, and dexterity impairments. Assistive technologies offer innovative options to get connected such as low-vision software for oversized monitors, speech amplification phones using landlines, and tremor stabilizing mouse controls (BT 2013; Watanabe et al. 2015; Fischer et al. 2014). More emphasis is needed on finding the optimal individualized approach for older adults to use digital technology rather than focusing on standard mobile devices (Fischer et al. 2014; Kuerbis et al. 2017). Additionally, technology approaches that combine data from those with and without Internet access, such as interactive voice response (IVR), should be considered for projects involving older adults (Verma et al. 2014; Piette et al. 2013).

There are some limitations to this report. The survey was not designed to study technology habits of older adults. The study participants do not reflect the demographic composition of the countries. People with bipolar disorder who did not seek professional help did not participate. People who did not understand the local language may not have participated. All data were selfreported and there was no follow-up discussion of responses. Many issues related to digital technology use by older adults were not discussed. These include the complex ethical challenges, quality of web sites and validity of digital tools for bipolar disorder (Bauer $\mathrm{M}$ et al. 2017), physiological effects of blue light exposure from digital devices (Bauer et al. 2018), and the potential for digital assistive tools to erode skills, decrease motivation, and promote a false sense of security (Schulz et al. 2015).

It is important to remember that technology will keep evolving (Arthur 2010). There will be disparities in the adaption of the new products and services, leaving digital equality a continuously moving target (Hilbert 2014, 2016). Young adults of today who are very comfortable using smartphones will continue to use smartphones as they age, and struggle with the new technologies available when they are seniors. The need to respect generational differences in the preferred means to access health information, minimize the burden of new technologies on older adults, and implement programs that expand access and lessen the negative impacts of digital inequalities will remain in the future.

In conclusion, the finding that many older adults with bipolar disorder do not use the Internet confirms the need for further investigation of technology habits, the efficacy of digital tools, and how best to determine who will use these tools appropriately and safely. Today, technology based tools and treatments are suitable for some but not all older adults with bipolar disorder. With government and health care providers increasingly relying on electronic communication, it is important to remember that many older adults do not use the Internet. As the population is aging and more health services are only available online, there is concern about growing health disparities for older adults with bipolar disorder. Mental health experts should contribute to defining the appropriate role for technologies in the care of older adults with bipolar disorder.

\section{Authors' contributions}

$J C, R B, T G$ and $M B$ a designed the study. MA, RA, RB, MB, YB, AB, APC, EYWC, CC, SC, JC, AC, RD, SD, AD, BE, AF, JG, JG, JG, MJG, AG, GMG, PG, HH, SH, CH, DH-M, VK, GK, BL, CL, ERL, UL, RW, AHL, ÂM-S, BM, SM, RM, TN, REN, CO'D, YO, YO, PP, $A R, P R, J K R, K S, B S, E S, C S, S S, A H S, K S, A S, P T, Y T, L T, J V, E V, M V, B V$, and $M Z$ were involved with data collection. TG provided data analysis. RB, JC, TG, PCW and MBa were involved in the draft manuscript and initial review. All authors read and approved the final manuscript.

\section{Author details}

${ }^{1}$ Department of Psychiatry and Psychotherapy, University Hospital Carl Gustav Carus, Technische Universität Dresden, Dresden, Germany. ${ }^{2}$ ChronoRecord Association, Fullerton, CA, USA. ${ }^{3}$ Bipolar Disorder Program, Neuroscience Institute, Favaloro University, Buenos Aires, Argentina. ${ }^{4}$ AMEOS Klinika Holstein, Neustadt, Germany. ${ }^{5}$ Department of Psychiatry, Dalhousie University, Halifax, NS, Canada. ${ }^{6}$ Unit of Clinical Pharmacology, University Hospital of Cagliari, Cagliari, Italy. ${ }^{7}$ Discipline of Psychiatry, School of Medicine, University of Adelaide, Adelaide, SA, Australia. ${ }^{8}$ School of Medicine, IMPACT Strategic Research Centre, Deakin University, Geelong, VIC, Australia. ${ }^{9}$ University Hospital Geelong, Barwon Health, Geelong, VIC, Australia. ${ }^{10}$ Department of Psychiatry, The University of Melbourne, Parkville, VIC, Australia. ${ }^{11}$ Florey Institute of Neuroscience and Mental Health, Parkville, VIC, Australia. ${ }^{12}$ Orygen Youth Health Research Centre and the National Centre of Excellence in Youth Mental Health, Parkville, VIC, Australia. ${ }^{13}$ Department of Psychiatry, Faculty of Health Sciences, Ben Gurion University of the Negev; Beer Sheva Mental Health Center, Beer Sheva, Israel. ${ }^{14}$ Department of Psychiatry, University of Oxford, Warneford Hospital, Oxford, UK. ${ }^{15}$ Section of Neurosciences and Clinical Pharmacology, Department of Biomedical Sciences, University of Cagliari, Cagliari, Sardinia, Italy. ${ }^{16}$ Department of General Adult Psychiatry, Castle Peak Hospital, Hong Kong, China. ${ }^{17}$ AP-HP, Hôpitaux Universitaires Henri-Mondor, Créteil, France. ${ }^{18}$ Department of Molecular Medicine and Department of Mental Health (DAl), University of Siena and University of Siena Medical Center (AOUS), Siena, Italy. ${ }^{19}$ Bipolar Disorder Research Program, Department of Psychiatry, University of São Paulo Medical School, São Paulo, Brazil.

${ }^{20}$ Department of Psychiatry, University of Calgary, Calgary, Canada. ${ }^{21}$ AP-HP, Hôpitaux Universitaires Henri-Mondor, INSERM U955 (IMRB), Université Paris Est, Créteil, France. ${ }^{22}$ Department of Psychiatry, University Hospital of Alava, University of the Basque Country, CIBERSAM, Vitoria, Spain. ${ }^{23}$ Department of Affective Disorders, Q, Mood Disorders Research Unit, Aarhus University Hospital, Aarhus, Denmark. ${ }^{24}$ Department of Psychiatry and Biobehavioral Sciences, Semel Institute for Neuroscience and Human Behavior, University of California Los Angeles (UCLA), Los Angeles, CA, USA. ${ }^{25}$ Mood Disorders Center of Ottawa, Ottawa, Canada. ${ }^{26}$ Department of Psychiatry, University of Toronto, Toronto, ON, Canada. ${ }^{27}$ Department of Psychiatry, Tokyo Metropolitan Matsuzawa Hospital, Setagaya, Tokyo, Japan. ${ }^{28}$ Department of Psychiatry, Cumming School of Medicine, University of Calgary, Calgary, Canada. ${ }^{29}$ Unité Perception et Mémoire, Institut Pasteur, F-75015 Paris, France. ${ }^{30}$ Bipolar Disorders Program, Hospital Clinic, University of Barcelona, IDIBAPS, CIBERSAM, Barcelona, Catalonia, Spain. ${ }^{31}$ Department of Clinical Psychology, NIMHANS, Bangalore 560029, India. ${ }^{32}$ Leicestershire Partnership NHS Trust, Leicester, UK. ${ }^{33}$ Institute of Clinical Research, Research Unit of Psychiatry, University of Southern Denmark, Odense, Denmark. ${ }^{34}$ Department of Psychiatry, Psychiatry in the Region of Southern Denmark, Odense, Denmark. ${ }^{35}$ Aalborg University Hospital, Psychiatry, Aalborg, Denmark. ${ }^{36}$ Department of Clinical Medicine, Aalborg University, Aalborg, Denmark. ${ }^{37}$ Department of Psychiatry, Wroclaw Medical University, Wroclaw, Poland. ${ }^{38}$ Department of Neuroscience and Mental Health, Federal University of Bahia, Salvador, Brazil. ${ }^{39}$ Michigan State University College of Human Medicine, Traverse City Campus, Traverse City, MI, USA. ${ }^{40}$ Department of Psychiatry, University of California San Diego, San Diego, CA, USA. ${ }^{41}$ Affective Disorders Research Project, Tokyo 
Metropolitan Institute of Medical Science, Setagaya, Tokyo, Japan. ${ }^{42}$ Department of Psychiatry, Psychosomatic Medicine and Psychotherapy, University Hospital Frankfurt, Goethe-University Frankfurt am Main, Frankfurt, Germany. ${ }^{43}$ Department of Adult Psychiatry, Poznan University of Medical Sciences, Poznan, Poland. ${ }^{44}$ Department of Psychiatry, University of Missouri Kansas City School of Medicine, Kansas City, MO, USA. ${ }^{45}$ Croton on Hudson, NY, USA. ${ }^{46}$ Department of Psychological Medicine, Faculty of Medicine, University of Malaya, Kuala Lumpur, Malaysia. ${ }^{47}$ City of Helsinki, Department of Social Services and Health Care, Psychiatry, Helsinki, Finland. ${ }^{48}$ Department of Psychiatry, Department of Medicine, University of Hong Kong, Hong Kong, China. ${ }^{49}$ McLean Hospital and Harvard Medical School, Boston, MA, USA. ${ }^{50}$ Lucio Bini Center, Cagliari, Rome, Italy. ${ }^{51}$ Psychiatric Center Copenhagen, Copenhagen, Denmark. ${ }^{52}$ Department of Psychiatry, NIMHANS, Bangalore 560029, India.

${ }^{53}$ Department of Psychology, Chapman University, Orange, CA, USA.

\section{Acknowledgements}

We thank Daniela Jany for preparing submission files and assisting with manuscript submission.

\section{Competing interests}

Michael Berk is supported by a National Health and Medical Research Council (NHMRC) Senior Principal Research Fellowship (Grant Number 1059660).

René E. Nielsen has received research grants from $\mathrm{H}$. Lundbeck and Otsuka Pharmaceuticals for clinical trials, received speaking fees from BristolMyers Squibb, Astra Zeneca, Janssen and Cilag, Lundbeck, Servier, Otsuka Pharmaceuticals, and Eli Lilly and has acted as advisor to Astra Zeneca, Eli Lilly, Lundbeck, Otsuka Pharmaceuticals, Takeda, and Medivir.

Rasmus W. Licht has received research grant from Glaxo Smith Kline, honoraria for lecturing from Pfizer, Glaxo Smith Kline, Eli Lilly, Astra-Zeneca, Bristol-Myers Squibb, Janssen Cilag, Lundbeck, Otsuka, Servier and honoraria from advisory board activity from Glaxo Smith Kline, Eli Lilly, Astra-Zeneca, Bristol-Myers Squibb, Janssen Cilag, and Sunovion. The other authors declare that they have no competing interests.

\section{Availability of data and materials}

The survey questionnaire was published. Sharing of data beyond the study was not approved by ethics boards or participants.

\section{Consent for publication}

All authors contributed to and approved the final manuscript, and gave their consent for publication.

\section{Ethics approval and consent to participate}

The study was approved by institutional review boards according to local requirements.

\section{Funding}

We acknowledge support by the Open Access Publication Funds of the SLUB/ TU Dresden (Grant No. IN-1502335).

\section{Publisher's Note}

Springer Nature remains neutral with regard to jurisdictional claims in published maps and institutional affiliations.

Received: 14 May 2018 Accepted: 1 August 2018

Published online: 04 September 2018

\section{References}

Agree EM. The potential for technology to enhance independence for those aging with a disability. Disabil Health J. 2014;7(1 Suppl):S33-9.

Anderson M, Perrin A. Tech adoption climbs among older adults. Pew Research Centre. 2017. http://www.pewinternet.org/2017/05/17/tech-adoptionclimbs-among-older-adults/. Accessed 30 Mar 2018.

Andrus MR, Roth MT. Health literacy: a review. Pharmacotherapy. 2002;22:282-302
Arthur WB. What is technology and how does it evolve? New York Academy of Sciences Magazine. 2010. https://www.nyas.org/magazines/winter-2010/ what-is-technology-and-how-does-it-evolve/. Accessed 6 July 2018.

Bauer M, Glenn T, Monteith S, Bauer R, Whybrow PC, Geddes J. Ethical perspectives on recommending digital technology for patients with mental illness. Int J Bipolar Disord. 2017;5:6.

Bauer M, Glenn T, Monteith S, Gottlieb JF, Ritter PS, Geddes J, Whybrow PC. The potential influence of LED lighting on mental illness. World J Biol Psychiatry. 2018;19:59-73.

Bauer R, Conell J, Glenn T, Alda M, Ardau R, Baune BT, et al. Internet use by patients with bipolar disorder: results from an international multisite survey. Psychiatry Res. 2016;242:388-94.

Bauer R, Conell J, Glenn T, Alda M, Ardau R, Baune BT, et al. International multisite survey on the use of online support groups in bipolar disorder. Nord J Psychiatry. 2017;71:473-6.

British Telecommunications. Communication choices for deaf or hard of hearing people. 2013. https://btplc.com/inclusion/HelpAndSupport/Docum entsandDownloads/Communicationchoices/Fordeaforhardofhearingpeo ple/Communication_Choices_Deaf_Hard_Hearing.pdf. Accessed 30 Mar 2018.

Burnes D, Henderson CR Jr, Sheppard C, Zhao R, Pillemer K, Lachs MS. Revalence of financial fraud and scams among older adults in the United States: a systematic review and meta-analysis. Am J Public Health. 2017;107:e13-21.

Carlson EL. Phishing for elderly victims: as the elderly migrate to the Internet fraudulent schemes targeting them follow. Elder Law J. 2007;14:423-52.

CDC. CDC Brief addressing financial exploitation among people living with cognitive impairment and their caregivers: role of the public health and aging services networks. 2015. https://www.cdc.gov/aging/pdf/exploitati on-cognitive-impairment-brief-july-2015.pdf. Accessed 30 Mar 2018.

Chang J, McAllister C, McCaslin R. Correlates of, and barriers to, Internet use among older adults. J Gerontol Soc Work. 2015;58:66-85.

Choi NG, Dinitto DM. Internet use among older adults: association with health needs, psychological capital, and social capital. J Med Internet Res. 2013;15:e97.

Conell J, Bauer R, Glenn T, Alda M, Ardau R, Baune BT, et al. Online information seeking by patients with bipolar disorder: results from an international multisite survey. Int J Bipolar Disord. 2016;4:17.

Deloitte UK. Connected health. How digital technology is transforming health and social care. 2015. https://www2.deloitte.com/content/dam/Deloitte/ uk/Documents/life-sciences-health-care/deloitte-uk-connected-healt h.pdf. Accessed 30 Mar 2018.

FBI. FBl efforts to combat elder fraud. 2014. https://www.fbi.gov/news/testi mony/fbi-efforts-to-combat-elder-fraud. Accessed 30 Mar 2018.

FBI Internet Crime Center. 2016 Internet crime report. 2016. https://pdf.ic3. gov/2016_IC3Report.pdf. Accessed 30 Mar 2018.

Fischer SH, David D, Crotty BH, Dierks M, Safran C. Acceptance and use of health information technology by community-dwelling elders. Int J Med Inform. 2014;83:624-35.

Flynn KE, Smith MA, Freese J. When do older adults turn to the Internet for health information? Findings from the Wisconsin longitudinal study. J Gen Intern Med. 2006;21(12):1295-301.

Forsman AK, Nordmyr J. Psychosocial links between Internet use and mental health in later life: a systematic review of quantitative and qualitative evidence. J Appl Gerontol. 2017;36:1471-518.

Friemel TN. The digital divide has grown old: determinants of a digital divide among seniors. New Media Soc. 2016;18:313-31.

Gallagher S, Doherty DT. Searching for health information online: characteristics of online health seekers. J Evid Based Med. 2009;2:99-106.

GAO (United States Government Accountability Office). Internet pharmacies. Most rogue sites operate from abroad, and many sell counterfeit drugs. GAO-14-386T. 2014. http://www.gao.gov/assets/670/661177.pdf. Accessed 30 Mar 2018.

Gell NM, Rosenberg DE, Demiris G, LaCroix AZ, Patel KV. Patterns of technology use among older adults with and without disabilities. Gerontologist. 2015;55:412-21.

Gliddon E, Barnes SJ, Murray G, Michalak EE. Online and mobile technologies for self-management in bipolar disorder: a systematic review. Psychiatr Rehabil J. 2017:40:309-19.

Grimes GA, Hough MG, Mazur E, Signorella ML. Older adults' knowledge of Internet hazards. Educ Gerontol. 2010;36:173-92. 
Hall AK, Bernhardt JM, Dodd V. Older adults' use of online and offline sources of health information and constructs of reliance and self-efficacy for medical decision making. J Health Commun. 2015;20:751-8.

Hallett C, Gupta S, Priebe S. What do outpatients with schizophrenia and mood disorders want to learn about their illness? Psychiatr Serv. 2013;64:764-9.

Heo J, Chun S, Lee S, Lee KH, Kim J. Internet use and well-being in older adults. Cyberpsychol Behav Soc Netw. 2015;18:268-72.

Hidalgo-Mazzei D, Mateu A, Reinares M, Matic A, Vieta E, Colom F. Internetbased psychological interventions for bipolar disorder: review of the present and insights into the future. J Affect Disord. 2015;188:1-13.

Hilbert M. The bad news is that the digital access divide is here to stay: domestically installed bandwidths among 172 countries for 1986-2014. Telecomm Policy. 2016;40:567-81.

Hilbert M. Technological information inequality as an incessantly moving target: the redistribution of information and communication capacities between 1986 and 2010. J Assoc Inf Sci Technol. 2014;65:821-35.

Holtfreter K, Reisig MD, Pratt TC, Holtfreter RE. Risky remote purchasing and identity theft victimization among older Internet users. Psychol Crime Law. 2015:21:681-98.

Home Instead. Survey: Two-thirds of seniors have been scammed online. Homelnstead. 2017. https://www.homeinstead.com/370/blog/surve y-two-thirds-of-seniors-have-been-scammed-online. Accessed $30 \mathrm{Mar}$ 2018.

Hou J, Shim M. The role of provider-patient communication and trust in online sources in Internet use for health-related activities. J Health Commun. 2010;15(Suppl 3):186-99.

Kang HG, Mahoney DF, Hoenig H, Hirth VA, Bonato P, Hajjar I, et al. In situ monitoring of health in older adults: technologies and issues. J Am Geriatr Soc. 2010;58:1579-86.

Kobayashi LC, Wardle J, von Wagner C. Internet use, social engagement and health literacy decline during ageing in a longitudinal cohort of older English adults. J Epidemiol Community Health. 2015;69:278-83.

Kuerbis A, Mulliken A, Muench F, Moore AA, Gardner D. Older adults and mobile technology: factors that enhance and inhibit utilization in the context of behavioral health. Ment Health Addict Res. 2017. https://doi. org/10.15761/MHAR.1000136.

Lala SV, Sajatovic M. Medical and psychiatric comorbidities among elderly individuals with bipolar disorder: a literature review. J Geriatr Psychiatry Neurol. 2012;25:20-5.

Levine DM, Lipsitz SR, Linder JA. Trends in seniors' use of digital health technology in the United States, 2011-2014. JAMA. 2016;316:538-40.

Levine DM, Lipsitz SR, Linder JA. Changes in everyday and digital health technology use among seniors in declining health. J Gerontol A Biol Sci Med Sci. 2018;73:552-9.

Levy H, Janke AT, Langa KM. Health literacy and the digital divide among older Americans. J Gen Intern Med. 2015;30:284-9.

Lichtenberg PA, Sugarman MA, Paulson D, Ficker LJ, Rahman-Filipiak A. Psychological and functional vulnerability predicts fraud cases in older adults: results of a longitudinal study. Clin Gerontol. 2016;39:48-63.

Lovett KM, Mackey TK. Online threats to senior safety: the direct-to-consumer medical marketplace and elder abuse. NAELA J. 2013;9:91-113.

Lovett KM, Mackey TK, Liang BA. Evaluating the evidence: direct-to-consumer screening tests advertised online. J Med Screen. 2012;19:141-53.

Mackey TK, Liang BA. The global counterfeit drug trade: patient safety and public health risks. J Pharm Sci. 2011;100:4571-9.

Mackey TK, Nayyar G. Digital danger: a review of the global public health, patient safety and cybersecurity threats posed by illicit online pharmacies. Br Med Bull. 2016;118:110-26.
Medlock S, Eslami S, Askari M Arts DL, Sent D, de Rooij SE, et al. Health information — seeking behavior of seniors who use the Internet: a survey. J Med Internet Res. 2015;17:e10.

Monteith S, Glenn T. Automated decision-making and big data: concerns for people with mental illness. Curr Psychiatry Rep. 2016;18:112.

Monteith S, Glenn T, Bauer R, Conell J, Bauer M. Availability of prescription drugs for bipolar disorder at online pharmacies. J Affect Disord. 2016;193:59-65.

Monteith S, Glenn T. Searching online to buy commonly prescribed psychiatric drugs. Psychiatry Res. 2017;260:248-54.

Nimrod G. Older audiences in the digital media environment. Inf Commun Soc. 2017:20:233-49.

Park SG, Derman M, Dixon LB, Brown CH, Klingaman EA, Fang LJ, et al. Factors associated with shared decision-making preferences among veterans with serious mental illness. Psychiatr Serv. 2014;65:1409-13.

Patrizio A. Think older workers struggle with technology? Think again, $\mathrm{ClO}$ 2016. https://www.cio.com/article/3103893/it-industry/think-older -workers-struggle-with-technology-think-again.html. Accessed $30 \mathrm{Mar}$ 2018

Piette JD, Rosland AM, Marinec NS, Striplin D, Bernstein SJ, Silveira MJ. Engagement with automated patient monitoring and self-management support calls: experience with a thousand chronically ill patients. Med Care. 2013;51:216-23.

Powell J, Clarke A. Internet information-seeking in mental health: population survey. Br J Psychiatry. 2006;189:273-7.

Reeder B, Meyer E, Lazar A, Chaudhuri S, Thompson HJ, Demiris G. Framing the evidence for health smart homes and home-based consumer health technologies as a public health intervention for independent aging: a systematic review. Int J Med Inform. 2013;82:565-79.

Sajatovic M, Strejilevich SA, Gildengers AG, Dols A, Al Jurdi RK, Forester BP, et al. A report on older-age bipolar disorder from the international society for bipolar disorders task force. Bipolar Disord. 2015;17:689-704.

Sbaffi L, Rowley J. Trust and credibility in web-based health information: a review and agenda for future research. J Med Internet Res. 2017;19:e218.

Schulz R, Wahl HW, Matthews JT, De Vito Dabbs A, Beach SR, Czaja SJ. Advancing the aging and technology agenda in gerontology. Gerontologist. 2015;55:724-34.

Torous J, Summergrad P, Nassir Ghaemi S. Bipolar disorder in the digital age: new tools for the same illness. Int J Bipolar Disord. 2016;4:25.

Verma SK, Courtney TK, Lombardi DA, Chang WR, Huang YH, Brennan MJ, et al. Internet and telephonic IVR mixed-mode survey for longitudinal studies: choice, retention, and data equivalency. Ann Epidemiol. 2014:24:72-4.

Watanabe T, Yamaguchi T, Minatani K. Advantages and drawbacks of smartphones and tablets for visually impaired people: analysis of ICT user survey results. IEICE Trans Inform Syst. 2015;98:922-9.

White CM, Gummerum M, Wood S, Hanoch Y. Internet safety and the silver surfer: the relationship between gist reasoning and adults' risky online behavior. J Behav Decis Making. 2017;30:819-27.

WHO. Ageing and health. Fact Sheet 404. 2015. http://www.who.int/media centre/factsheets/fs404/en/. Accessed 30 Mar 2018.

Yu RP, Ellison NB, McCammon RJ, Langa KM. Mapping the two levels of digital divide: Internet access and social network site adoption among older adults in the USA. Inf Commun Soc. 2016:19:1445-64.

Zulman DM, Kirch M, Zheng K, An LC. Trust in the Internet as a health resource among older adults: analysis of data from a nationally representative survey. J Med Internet Res. 2011;13:e19. 